\title{
Lateral Limit of Superior Sagittal Sinus in Respect to External Part of Sagittal Suture
}

\author{
Pankaj Raj Nepal ${ }^{1}$, Birat Thapa Magar ${ }^{2}$ \\ ${ }^{1}$ Department of Neurosurgery, B and C Medical College Teaching Hospital and Research Center, \\ Birtamode, Jhapa, Nepal. \\ ${ }^{2}$ Department of Neurosurgery Unit -1, Punjab Institute of Neuroscience, Lahore General Hospital, Ferozepur \\ Road, Lahore, Pakistan.

\section{Correspondence:} \\ Dr. Pankaj Raj Nepal, FCPS, \\ Deputy Medical Director, \\ Head of Department, Department of Neurosurgery, \\ B and C Medical College Teaching Hospital and Research Center, Birtamode, Jhapa, Nepal. \\ Email: pankajrajnepal@ gmail.com \\ Phone no: +9779801098106
}

\begin{abstract}
Background: Sagittal suture has been used as an external landmark of superior sagittal sinus since the very beginning of neurosurgery. However, most of the time the sinus is not exactly under the suture line, rather, it has some displacement to one side. So, to analyze the variation of the lateral limit of superior sagittal sinus from the external part of sagittal sinus this study was performed. Materials and methods:Consecutive cases of MRI brain with contrast done in B\&C Medical College Teaching Hospital was collected over 3 months, Age, gender, right, and left lateral limits of the superior sagittal sinus from the sagittal suture at its mid-point was collected in preformed proforma. Mean and standard deviation was calculated for the continuous variables, ANOVA was done to evaluate the association of gender with the lateral limits of sinus and Pearson correlation was done to see the relation of age with the lateral limits of the sinus. All the analysis was done using IBM SPSS 20. Results: There were a total of 40 patients enrolled in the study. The mean age was 39.8 years with male $(75 \%)$ predominance. The lateral right limit of the superior sagittal sinus was up to $23 \mathrm{~mm}$ and in the left up to $17.1 \mathrm{~mm}$ from the outer limit of the sagittal suture. There was no significant association of gender with both the right and left limits of the superior sagittal sinus. Similarly, there was no significant correlation of age with the lateral limit of the superior sagittal sinus. Conclusion:The mean existence of superior sagittal sinus is $9.57 \mathrm{~mm}$ in the right to $5.78 \mathrm{~mm}$ in the left side from the outer limit of the sagittal suture. However, in extreme stances it's lateral limits can extend up to $17 \mathrm{~mm}$ in left to $23 \mathrm{~mm}$ in the right from the outer limit of the sagittal suture.
\end{abstract}

Key words: Alignment, Lateral limit, Sagittal suture, Superior sagittal sinus.

$\mathrm{F}$ rom the very starting of neurosurgery sagittal suture has played a role as an external landmark of superior sagittal sinus, the injury of which is a nightmare for the neurosurgeons..$^{1-4}$ Generally, superior sagittal sinus is thought to be just below the sagittal suture, however, there is evidence of it to be located with some displacement from the sagittal sutures in reality. ${ }^{5,6}$ Proper bloodless surgery needs absolute preservation of superior sagittal sinus during craniotomies. ${ }^{7}$ Hence, with the aim to identify the relation of the lateral limits of the superior sagittal

26

Date submitted: 11/0 4/2020

Date accepted: 09/05/2020 sinus in relation to the sagittal suture, this study has been performed.

\section{Methods and Materials:}

A cross-sectional analytical study was performed in patients attending to Neurosurgery department of B \& C Medical College Teaching Hospital from 1st April 2019 to 30th June 2019. Non-probability consecutive sampling was done and 40 cases who had undergone cranial MRI with contrast were selected for study with an aim to identify the

egneuro, Volume 02, Issue 02, 2020 
relation of lateral limits of the sagittal sinus in relation to the sagittal suture. All the cranial MRI was interpreted by the senior author and the limits of superior sagittal sinus, its midline, and the position of the sagittal suture was delineated. Data were collected in terms of age, gender, right and left lateral limits of the superior sagittal sinus from the sagittal suture at its mid-point was collected in preformed proforma (Figure 1). Patients with mass effect, obvious midline shift, or intracranial pathology like mass lesions were excluded from the study. Similarly, cases in which sagittal suture could not be clearly identified were also excluded from the study.

Mean and standard deviation was calculated for the continuous variables, ANOVA was done to evaluate the association of gender with the lateral limits of superior sagittal sinus and Pearson correlation was done to see the relation of age with the lateral limits of the sinus. All the analysiswasdone using IBM SPSS 20.

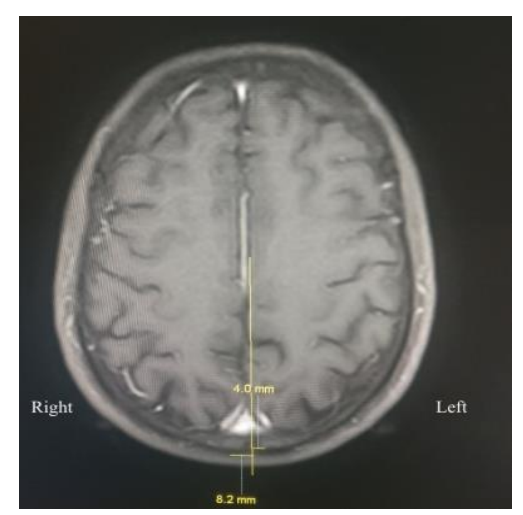

Figure 1: Measurement of lateral limits of superior sagittal sinus

\section{Results:}

(There was altogether 54 contrast-enhanced cranial MRI performed during the study period out of which 14 were excluded.) Thus altogether 40 patients were enrolled in the study. The mean age was 39.8 (SD 15.5) years with $75 \%$ male in the study (Figure 2).

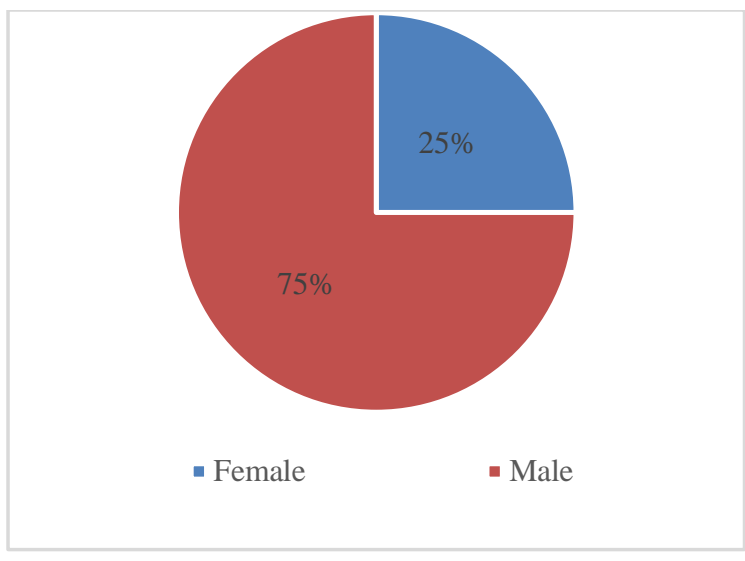

Figure 2: Distribution of gender

The mean lateral right limit of the superior sagittal sinus was $9.57 \mathrm{~mm}$ (SD $5.41 \mathrm{~mm}$ ), which ranged between $0.83 \mathrm{~mm}$ to $23 \mathrm{~mm}$ to the right. Similarly, the mean lateral left limit was $5.78 \mathrm{~mm}$ (SD $4.86 \mathrm{~mm}$ ) which ranged between $-4 \mathrm{~mm}$ to $17.1 \mathrm{~mm}$ from the outer limit of sagittal suture (Table 1).

Table 1: Mean and standard deviation of age and limits ofsinus

\begin{tabular}{lcccc}
\hline & $\begin{array}{c}\text { Minim } \\
\text { um }\end{array}$ & $\begin{array}{c}\text { Maxim } \\
\text { um }\end{array}$ & Mean & $\begin{array}{c}\text { Std. } \\
\text { Deviati } \\
\text { on }\end{array}$ \\
\hline age & 14 & 90 & 39.80 & 15.547 \\
$\begin{array}{l}\text { Right } \\
\text { limit }\end{array}$ & .83 & 23.00 & 9.5713 & 5.41198 \\
$\begin{array}{l}\text { Left } \\
\text { limit }\end{array}$ & -4.00 & 17.10 & 5.7830 & 4.85896 \\
\hline
\end{tabular}

There was no significant association of gender with both the right and left limits of the superior sagittal sinus (Table 2). 
Table 2: Distribution of gender.

\begin{tabular}{lccccc}
\hline \multicolumn{1}{c}{ gender } & N & Mean & $\begin{array}{c}\text { Std. } \\
\text { Deviati } \\
\text { on }\end{array}$ & $\begin{array}{c}\text { P- } \\
\text { Value }\end{array}$ \\
\hline $\begin{array}{l}\text { right_lim } \\
\text { it }\end{array}$ & Male & 30 & $\begin{array}{c}9.904 \\
0\end{array}$ & 5.84771 & 0.249 \\
& & & 0 & & \\
left_limit & Mema & 10 & 8.573 & 3.90628 & \\
& Me & & 0 & & \\
& & & 0 & & \\
& Fema & 10 & 5.801 & 4.71771 & \\
& le & & 0 & & \\
\hline
\end{tabular}

Similarly, there was no significant correlation of age with either of the lateral limit of the superior sagittal sinus (Table 3 and Table 4).

Table 3: Correlation of age with right limit of the superior sagittal sinus

\begin{tabular}{|c|c|c|c|}
\hline & \multicolumn{2}{|c|}{ Correlations } & \multirow[b]{2}{*}{ Right } \\
\hline & & age & \\
\hline \multirow[t]{3}{*}{ age } & Pearson & 1 & .111 \\
\hline & Sig. & & .496 \\
\hline & $\mathrm{N}$ & 40 & 40 \\
\hline \multirow{3}{*}{$\begin{array}{l}\text { Right } \\
\text { limit }\end{array}$} & Pearson & .111 & 1 \\
\hline & Sig. & .496 & \\
\hline & $\mathrm{N}$ & 40 & 40 \\
\hline
\end{tabular}

Table 4: Correlation of age with the left limit of superior sagittal sinus

\begin{tabular}{|c|c|c|c|c|}
\hline & \multicolumn{3}{|c|}{ Correlations } & \multirow[b]{2}{*}{ Left limit } \\
\hline & & & age & \\
\hline \multirow[t]{3}{*}{ age } & Pearson & & 1 & -.055 \\
\hline & Sig. & (2- & & .736 \\
\hline & $\mathrm{N}$ & & 40 & 40 \\
\hline \multirow[t]{3}{*}{ Left limit } & Pearson & & -.055 & 1 \\
\hline & Sig. & (2- & .736 & \\
\hline & $\mathrm{N}$ & & 40 & 40 \\
\hline
\end{tabular}

\section{Discussion:}

The sagittal suture is formed between two parietal bones and runs between coronal and lambdoid suture in the midline. ${ }^{1}$ Historically, it is a very good landmark of the superior sagittal sinus and most of the neurosurgeons rely on this landmark for parafalcine parasagittal craniotomies. ${ }^{8,9}$ However; there are reports of sinus injury during such craniotomy which might be due to its presence not being exactly under the sagittal sinus rather displaced to one side or due to its morphological variations. $^{10}$ Previous studies done by cadaveric dissection showed around $10-11 \mathrm{~mm}$ of maximum displacement mainly to the right side of the superior sagittal sinus from the sagittal suture.6 However, in this study there was a maximum displacement of lateral limits up to $23 \mathrm{~mm}$ to the right and $17 \mathrm{~mm}$ to the left with its mean displacement similar to the previous studies. This value could help the neurosurgeon in the setting of emergency craniotomy or elective craniotomies in the absence of Neuronavigation for proper placement of burrs and craniotome to prevent sinus injury. ${ }^{11,}{ }^{12}$ In the literature the safety limit of placement of burr hole is somewhere around 15 $\mathrm{mm}$ from the midline sagittal suture; however, as for the finding in our study the burr hole placed 25 $\mathrm{mm}$ to the right and $20 \mathrm{~mm}$ to the left seems necessary to prevent sinus injury in all cases of craniotomy around superior sagittal sinus because even a small dural tear over the lateral limits of 
sinus will also lead to devastating bleeding or air embolism. $^{13}$

Dural venous sinus seems to make a groove in the inner table of the skull bone and it corresponds to the size of the sinus but it doesn't seem to grow or shrink with the advancing age. ${ }^{14}$ Similarly, As noted in previous studies, in this study the relation of a lateral limit of superior sagittal sinus and sagittal suture neither seems to be associated with advancing age nor with the gender. ${ }^{5,6}$

The small sample size and non-inclusion of various races and ethnic groups are the main limitation of this study. However, this may be the first morphometric study evaluating the limits of the sagittal sinus in Nepalese population and we believe that a more elaborate study with larger sample size and study of racial and ethnic variation of the limits of the superior sagittal sinus in relation to the sagittal suture would be better for future.

\section{Conclusion:}

The mean existence of superior sagittal sinus is $9.57 \mathrm{~mm}$ in the right to $5.78 \mathrm{~mm}$ in the left side from the outer limit of the sagittal suture. However, in extreme stances it's lateral limits can extend up to $17 \mathrm{~mm}$ in left to $23 \mathrm{~mm}$ in the right from the outer limit of the sagittal suture.

\section{References:}

1. Rice DP. Developmental anatomy of craniofacial sutures. InCraniofacial Sutures 2008 (Vol. 12, pp. 1-21). Karger Publishers.

2. Reis CV, Gusmão SN, Elhadi AM, Dru A, Tazinaffo U, Zabramski JM, Spetzler RF, Preul MC. Midline as a landmark for the position of the superior sagittal sinus on the cranial vault: an anatomical and imaging study. Surgical neurology international. 2015;6.

3. Meier U, Gärtner F, Knopf W, Klötzer R, Wolf O. The traumatic dural sinus injury-a clinical study. Acta neurochirurgica. 1992 Mar 1;119(1-4):91-3.

4. Wu JJ, Shih CJ. Unusual penetrating injury of the superior sagittal sinus. Surgical neurology. 1982 Jan 1;17(1):43-6.

5. Samadian M, Nazparvar B, Haddadian K, Rezaei O, Khormaee $\mathrm{F}$. The anatomical relation between the superior sagittal sinus and the sagittal suture with surgical considerations. Clinical neurology and neurosurgery. 2011 Feb 1;113(2):89-91.

6. Tubbs RS, Salter G, Elton S, Grabb PA, Oakes WJ. Sagittal suture as an external landmark for the superior sagittal sinus. Journal of neurosurgery. 2001 Jun $1 ; 94(6): 985-7$.

egneuro, Volume 02, Issue 02, 2020
7. Behera SK, Senapati SB, Mishra SS, Das S. Management of superior sagittal sinus injury encountered in traumatic head injury patients: analysis of 15 cases. Asian journal of neurosurgery. $2015 \mathrm{Jan} ; 10(1): 17$.

8. Mayfrank L, Gilsbach JM. Interhemispheric approach for microsurgical removal of olfactory groove meningiomas. British journal of neurosurgery. 1996 Jan 1;10(6):541-6.

9. Kim YB, Young WL, Lawton MT. Parafalcine and midline arteriovenous malformations: surgical strategy, techniques, and outcomes. Journal of neurosurgery. 2011 Apr 1;114(4):984-93.

10. Nepal PR, Rijal S. Morphological variation of the confluences of sinuses in head. J Neurol Neurophysiol. 2018 Sep, 9: 35. DOI: 10.4172/2155-9562-C5-073

11. Nepal PR, Rijal S. Outcome Following Decompressive Surgery for Malignant Middle Cerebral Artery Infarction. Eastern Green Neurosurgery. 2020 Jan 29;2(1):23-6.

12. Johnson RD, Maartens NF, Teddy PJ. Technical aspects of decompressive craniectomy for malignant middle cerebral artery infarction. Journal of Clinical Neuroscience. 2011 Aug 1;18(8):1023-7.

13. Rish BL. The repair of dural venous sinus wounds by autogenous venorrhaphy. Journal of neurosurgery. 1971 Oct 1;35(4):392-5.

14. Rijal S, Nepal PR, Bishokarma S, Ranabhat K, Gongal DN. Morphometric Relationship of the Transverse Sinus with Sigmoid Sinus Groove and Jugular Foramen. Nepal Journal of Neuroscience. 2018 Dec 31;15(3):49-53. 